\title{
Psychological impact of breast cancer; a study done in a Sri Lankan setting
}

\author{
Lakmini Mudduwa', Gayani Punchihewa ${ }^{2}$ \\ Department of Pathology ${ }^{1}$, Department of Psychiatry ${ }^{2}$, Faculty of Medicine, University of Ruhuna, Galle, \\ Sri Lanka \\ Correspondence: Dr. Lakmini Mudduwa (lakminimudduwa@yahoo.com)
}

\begin{abstract}
Introduction: Breast cancer is the commonest cancer in Sri Lanka. Our aim was to assess the magnitude of the psychological morbidity of breast cancer in our setting.

Methods: A self administered questionnaire and the 12 question General Health Questionnaire were used to collect data from a cohort of breast cancer patients. Out of 183 patients, 75 returned the duly filled questionnaire.

Results: The age range of the study sample was 24 to 83 years (mean 53.2). Psychological distress was experienced by $30.66 \%$ during the two year period following the diagnosis of breast cancer. Thirty four (48.6\%) participants claimed that they have experienced psychological distress sometime during the period following diagnosis up to the time of data collection. Only one had moderate depression. Most of them feared of future recurrences and concerned of inadequacy of information given by the healthcare team regarding the illness. Most of the patients adopted both positive and negative styles of coping. Nearly all (95.8\%) were satisfied with the family support.

Conclusions: The present study reveals that a significant proportion of patients had distress related to breast cancer at the time of filling the questionnaire. A significantly high proportion of patients receive satisfactory family support to cope with the illness. Most of them have developed mixed positive and negative coping styles towards the illness. In a significant proportion of patients' distress was related to uncertainty about the future recurrences.
\end{abstract}

Key words: Breast cancer, Psychological impact

\section{Introduction}

Breast cancer has been studied from different perspectives world over. There are many studies done in Sri Lanka as well, on different aspects of breast cancer including pathological reporting, clinico-pathological features and prevalence. Published data on psychological impact of breast cancer in our country are very few although there are many in the world literature. Research in this dimension has been useful although the results have been found to vary depending on the sample, the methodology and the timing of the research (1).
It is believed that a significant proportion of breast cancer patients' experiences psychological morbidity in the first year after a breast cancer diagnosis (2) and there can be a marked variation in the psychological morbidity during the first year (3). The psychological impact of breast cancer may be different to any other cancer. This is because women who have had mastectomies experience altered body image. Thus diagnosis of breast cancer leads them to feel helpless, anxious and depressed (4). As we now see younger patients with breast cancer the issue of change in body image could have a bigger influence on the psychological morbidity. 
Women experiencing breast cancer are confronted with a life threatening disease and find themselves in a situation that changes and restricts their lives psychologically, physically and socially (5). Acceptance of the illness, social interaction or the support, physical changes and uncertainty are some of the problems that a breast cancer patient faces (6). Therefore patients need to have considerable adjustment brought into their lives. It is important to study the psychological impact of breast carcinoma to identify the magnitude and then to design psychosocial interventions.

The main aim of this study was to assess the psychological impact of breast carcinoma which will influence designing an appropriate psychological support system for breast cancer patients in Sri Lanka.

\section{Methods}

This study was carried out in the Diagnostic Immunohistochemistry Laboratory, Department of Pathology, Faculty of Medicine, University of Ruhuna, Galle, Sri Lanka. This is the only laboratory in the Southern Province which performs immunohistochemical markers of breast cancer; hence the majority of breast cancer patients in the Southern Province are referred to this specialised laboratory. All breast cancer patients who sought the services of the Diagnostic Immunohistochemistry Laboratory from June 2006 to October 2007 were included in the study.

\section{Data collection}

Data collection was done through a self administered questionnaire completed and returned by the participant. The questionnaire was posted to the participants along with a letter from the researchers guaranteeing confidentiality and anonymity and a stamped addressed envelop.

The questionnaire had three sections. The Section 1 contained questions on patient's demographic details including age, marital status and educational level. The Section 2 asked a series of questions on the duration following diagnosis, treatment received, side effects experienced and six questions related to the coping style. The revised version of the Mental Adjustment to Cancer Scale was modified and only 6 questions of the Mental Adjustment to Cancer Scale representing the six styles of coping with cancer (fighting spirit- positive orientation to illness, fighting spirit-minimising illness, helplessness, anxious preoccupation, fatalistic and avoidance) were included to maximize the patients' compliance in filling the questionnaire (4). The questions have been translated into Sinhala by the authors. Likert scale 1,2,3,4 from left to right was used to assess the response to find which coping style the patient adopted.

The Section 3 is the General Health Questionnaire (GHQ) which contained 12 questions. It was used as a self administered questionnaire to assess the psychological morbidity. The Sinhala translation of the twelve questions was selected from the Sinhala translation of the 30 question GHQ which has already been validated. The questionnaire was pretested before using on the study sample.

The score range for the 12 question GHQ was 0-36. A score of $>15$ was taken as evidence of distress and $>20$ considered as evidence of severe problems and psychological distress. All patients who had a score of more than 15 were invited for an interview with the second author who is a consultant psychiatrist practicing in a teaching hospital. The interviews were held in a quiet room to ensure privacy and confidentiality. The aim of the interview was to identify the group of patients with depression on clinical grounds. Diagnosis of depression was made using the ICD-10 (International classification of diseases). Informed written consent was obtained from the patients before enrolling for the study. Ethical approval for the study was obtained from the Ethical Review Committee of our institution.

\section{Results}

The questionnaire was posted to consecutive 183 patients who sought services of the laboratory. Only 75 patients completed and returned the questionnaire (41\% response rate). The majority of patients 70/75 (96\%) were Sinhalese and $94.6 \%$ were Buddhists. The age range of the study sample (those who returned the questionnaire) was 24 to 83 years (mean 53.2 and SD 11.39). There were six patients $(8 \%)$ who were less than 40 years. Most of the patients ( 28 of 75 or $37.3 \%$ ) were between $41-50$ years while 24 patients (32\%) were 51-60 years. Seventeen patients 
$(22.7 \%)$ were more than 60 years. Since the number of patients who were less than 40 years was small it was not assessed separately for psychological morbidity.

All the subjects included in the study were females. The majority of them were married, (56 of 75 or $74.66 \%$ ). There were seven unmarried, three divorced and nine widows in the study sample. Sixty seven $(89.3 \%)$ of them had children. There were five patients $(6.7 \%)$ who had no formal education while the majority $43(57.3 \%)$ had completed at least General Certificate Examination Ordinary Level (table 1).

There was only one patient in the study sample who did not know that she was having a breast cancer. All the others $(98.7 \%)$ were aware of their illness. The majority of patients ( 55 of 75 or $73.3 \%$ ) were within the first year following the diagnosis of breast cancer (table 2).

According to the score obtained for the GHQ the majority (50 of 75 or $66.7 .2 \%$ ) did not have distress as the score was 15 or less. Twenty three patients $(30.7 \%)$ obtained more than 15 indicating distress. Out of the 23 patients 10 had a score of more than 20 suggesting severe problems and psychological distress. Out of the 23 patients who were invited for an interview only eleven participated in the interview with the psychiatrist. The reasons for poor participation at the interview were not clear.
No statistically significant correlation was found between the score obtained for the GHQ and the duration following diagnosis ( $\mathrm{p}$ value $=0.06)($ table 2 ). The level of education, age, the number of children, marital status also did not show any relationship with the GHQ score.

The patients were asked whether they had experienced any psychological distress following diagnosis. Only 70 patients had answered this question and 34 (48.6\%) admitted that they had such problems. There was a statistically significant correlation between the response to this question and the score obtained for GHQ ( $p=0.001)$ although the GHQ assessed only the mental status of the patient at the time and during the last few weeks of administering the questionnaire. None of the patients had a history of psychiatric illness.

All 75 patients had undergone mastectomy. Sixty two out of seventy patients $(88.6 \%)$ had chemotherapy but there was no association with the score for the GHQ. Out of 67 patients who answered the question on radiotherapy, 35 (52.2\%) had undergone radiotherapy. Neither the treatment given nor the duration following treatment had any correlation with the score for the GHQ.

The questionnaire specifically asked whether they were happy with the support they received from the family to cope with the breast cancer. Only three patients were not satisfied while 69/72 (95.8\%) agreed giving either 1 or 2 in the Likert scale.

Table 1: Duration following the diagnosis of breast cancer and the GHQ score of survivors who answered the questionnaire

\begin{tabular}{llllll}
\hline $\begin{array}{c}\text { Duration } \\
\text { (months) }\end{array}$ & $\begin{array}{c}\text { Number } \\
\text { of patients }\end{array}$ & Percentage & $\begin{array}{c}\text { Cumulative } \\
\text { percentage }\end{array}$ & \multicolumn{2}{c}{ GHQ score } \\
\hline $0-6$ & 19 & 25.3 & 25.3 & $14 / 18(77.8 \%)$ & $4 / 18(22.2 \%)$ \\
$7-12$ & 36 & 48 & 73.3 & $25 / 35(71.4 \%)$ & $10 / 35(28.5 \%)$ \\
$13-18$ & 12 & 16 & 89.3 & $5 / 12(41.7 \%)$ & $7 / 12(58.3 \%)$ \\
$19-24$ & 5 & 6.7 & 96 & $4 / 5(80 \%)$ & $1 / 5(20 \%)$ \\
$>24$ & 3 & 4 & 100 & $2 / 3(66.7 \%)$ & $1 / 3(33.3 \%)$ \\
\hline
\end{tabular}


Table 2: Level of education of participants of the survey

\begin{tabular}{lccc}
\hline Education & $\begin{array}{c}\text { Number } \\
\text { of } \\
\text { patients }\end{array}$ & percentage & $\begin{array}{c}\text { cumulative } \\
\text { percent }\end{array}$ \\
\hline $\begin{array}{l}\text { No formal } \\
\text { education }\end{array}$ & 5 & 6.7 & 6.7 \\
Grade 1-5 & 14 & 18.7 & 25.3 \\
Grade & 13 & 17.3 & 42.7 \\
6-10 & & 40.0 & 82.7 \\
$\begin{array}{l}\text { Completed } \\
\text { O/Level }\end{array}$ & 30 & 16 & 98.7 \\
$\begin{array}{l}\text { Completed } \\
\text { A/Level }\end{array}$ & 12 & 1.3 & 100 \\
$\begin{array}{l}\text { Higher } \\
\text { education }\end{array}$ & 1 & & \\
\hline
\end{tabular}

$\mathrm{O} / \mathrm{L}$ - Ordinary level Examination

$\mathrm{A} / \mathrm{L}$-Advanced Level Examination

\section{Coping style}

Out of the six questions asked five were analysed and the answer to the sixth question was not considered for the analysis since the authors felt that the Sinhala translation of the corresponding question was ambiguous and did not inquire fatalistic behaviour.
Therefore fatalistic behaviour could not be assessed. The majority in the study sample appeared to adopt fighting spirit-positive orientation to illness as well as minimising illness as coping styles. However there were a significant proportion of patients who tend to adopt helplessness, anxious preoccupation and avoidance as coping behaviours (table 3). A statistically significant correlation was found between the score for GHQ ( $<=15$ and $>15$ groups) and the results for fighting spirit minimizing behaviour, helpless and anxious preoccupation ( $p$ value $=0.033,0.031$ and 0.031 respectively).

\section{Interview with the patients with distress}

Out of eleven patients who participated in the interviews conducted by the psychiatrist, only one was found to be having depression which was moderate in degree. The most striking finding was that the distress was related to the fear of recurrence of the disease which was present in five out of the 11 patients. Two patients who had GHQ score of $>15$ had filled the questionnaire at the time of getting chemotherapy and their answers at the interview which was held after completing the course of chemotherapy gave a lower GHQ score. The discussions with the patients at the interview revealed that lack of information regarding the prognosis of their illness was the main concern of most of the patients.

Table 3: Coping Styles adopted by the survivors of breast cancer

\begin{tabular}{lrr}
\hline Coping style and the statement appeared in the & \multicolumn{2}{c}{ Likert Scale } \\
questionnaire & $\mathbf{1 - 2}$ (agree) & 3-4 (disagree) \\
\hline $\begin{array}{l}\text { Fighting spirit - positive orientation to illness } \\
\text { I believe that my positive attitude will benefit my health. }\end{array}$ & $68 / 71(95.7 \%)$ & $3 / 71(4.2 \%)$ \\
Fighting spirit -minimising illness & $71 / 73(97.2 \%)$ & $2 / 73(2.8 \%)$ \\
$\begin{array}{l}\text { I try to lead a normal life as before. } \\
\text { Helpless }\end{array}$ & $59 / 71(83.1 \%)$ & $12 / 71(16.9 \%)$ \\
$\begin{array}{l}\text { I feel completely at a loss about what to do } \\
\text { Anxious preoccupation }\end{array}$ & $41 / 72(56.9 \%)$ & $31 / 71(43.1 \%)$ \\
$\begin{array}{l}\text { I worry about cancer returning or getting worse } \\
\text { Avoidance }\end{array}$ & $45 / 71(63.4 \%)$ & $26 / 71(36.6 \%)$ \\
I don't really believe I had cancer & & \\
\hline
\end{tabular}




\section{Discussion}

Breast cancer is the most common cancer in Sri Lanka (7). It is the commonest cancer in females worldwide (8). In Sri Lanka, a significant development on par with the developed countries has been seen in the field of management of breast cancer especially in the areas of investigations, diagnosis, pathological reporting and treatment. Despite these advances diagnosis of and recovery from breast cancer remain highly stressful (8). There is considerable evidence that breast cancer and its treatment are associated with problems with body image (8). In the present study $30.7 \%$ had a GHQ score more than 15 indicating distress. Nearly half of the sample; $48.6 \%$ admitted that they experienced psychological distress sometime during the period following the diagnosis of breast cancer.

Compas et al (8) found that symptoms of anxiety and depression near the time of diagnosis are typically seen in $30 \%$ to $40 \%$ of patients, a rate that is approximately three to four times that found in the general population. Rates of psychiatric diagnose are less clear because of the variation in the methodologies adopted and the timing of the study. A study done at Dartmouth- Hitchcock Medical Centre in Lebanon using 236 patients who had just learned that they had breast cancer revealed emotional distress in nearly half of them interfering with their daily lives (9). More than one in ten had major depression. A $47 \%$ of women who reported emotional stress had suffered worry, fear, nervousness, sadness and depression. Nearly all of these women were troubled by uncertainties about treatment and physical symptoms (9).

Another study done by Burgess and colleagues to examine the prevalence of depression and anxiety in women with early breast cancer in the five years after diagnosis revealed depression, anxiety or both in $50 \%$ in the year after diagnosis, $25 \%$ in the second, third, and fourth years, and 15\% in the fifth year (10). Clinical factors were not associated with depression and anxiety at any time (10). In our study 22 out of 23 who had psychological distress were within the two years following the diagnosis of breast cancer.

The experience of the side effects of chemotherapy and radiotherapy has been found to be traumatic. In the present study there was no association between the psychological distress and the type of treatment given as a majority experienced side effects of either chemotherapy and / or radiotherapy. The reason may be that the study was not done with any particular timing with regard to chemotherapy or radiotherapy. The change in the body image following surgery is also associated with distress (8) although it may be less with breast conserving surgeries and in some cultural settings. We did not directly ask the patients whether the change in the body image was a worry. The information gathered from the questionnaire was insufficient to further assess the relationship between the treatment and distress.

The vast majority was adopting fighting spirit as coping style in the present study. However it appears that a significant proportion adopts negative coping strategies like helplessness, anxious preoccupation and avoidance as well. Greer et al found that recurrence free survival was significantly more common among patients who reacted to cancer with denial or fighting spirit than among patients who responded with stoic acceptance and helplessness (11). Positive mood is reported to be associated with longer survival while negative mood with a shorter survival (12).

Although the patients were informed of the illness they have, at the interview patients with distress revealed that inadequacy of information received made them anxious and stressful. Majority of them had uncertainties about future recurrences.

Provision of adequate information on the disease has been identified as an indispensable element of effective treatment for any chronic disease (13). There are many resources available for information however patients rely highly on the healthcare provider for good quality personalized information (13). In Sri Lanka ever busy surgical and oncology clinics may not provide the opportunity for the doctor to give all necessary information to the cancer patients.

It has been found that support given to women with breast cancer has a positive effect upon their reactions to the illness and may even prolong their survival (1). Lack of intimate confiding support predicts protracted depression and anxiety in breast cancer patients (10). The present study reveals that the majority of patients are happy with the family support received in coping with the illness which may have helped them to adopt positive coping styles. However the support extended by the healthcare workers needs to be expanded to cover the psychological needs apart from providing the best available treatment. This study emphasizes the need 
for a support mechanism which helps breast cancer patients to be aware of prognosis and educated to cope with side effects. It should include a system of psychological support as well.

\section{Limitations}

Our questionnaire did not inquire about the satisfaction of the patient with information provided by the healthcare workers to substantiate the comments made by many who participated in the interview. Therefore we cannot make conclusions on the degree of satisfaction on the information received by the patients included in the study sample. The failure to interpret the results of the fatalistic behaviour was due to a translation error. The Sinhala version of the MAC scale has not been validated, however the correlations observed with the score for the GHQ validates some of the questions. The number of the patients who attended the interviews with the psychiatrist was not adequate to draw conclusions on the prevalence of depression among those who had higher GHQ score.

\section{Conclusions}

The present study reveals that a significant proportion of the sample had distress related to breast cancer at the time of filling the questionnaire. A higher percentage had distress sometime during the period following diagnosis of breast cancer. A significantly high proportion of patients receive satisfactory family support to cope with the illness. Most of them have developed mixed positive and negative coping styles towards the illness. In a significant proportion of patients' distress was related to uncertainty about the future recurrences which may be one of the reasons for prevailing psychological morbidity in spite of good family support in a traditionally supportive culture. Inadequate transfer of information from the healthcare personnel to the patient may also contribute to the stress and hence the distress.

The present study emphasizes the need to develop a well designed support system which will educate patients on their illness to reduce the psychological morbidity of breast carcinoma.

\section{Acknowledgement}

Mrs. Dhammika Gunawardhana and Mr. LDN Nilupul for the assistance in collecting data and Mrs. Indrani Lokuge for typing the questionnaire.

\section{References}

1. Lindop E, Cannon S. Evaluating the self assessed support needs of women with breast cancer. Journal of Advanced Nursing 2001 Jun; 34: 760-771.

2. Nosarti C, Roberts JV, Crayford T, McKenzie K, David AS. Early psychological adjustment in breast cancer patients: a prospective study. Journal of Psychosomatic Research 2002 Dec; 53: 1123-1130.

3. Millar K, Purushotham AD, McLatchie E, George WD, Murray GD. A one year prospective study of individual variation in distress, and illness perceptions, after treatment for breast cancer. Journal of Psychosomatic Research 2005 Apr; 58: 335-342.

4. Link L.B, Robbins L, Mancuso CA, Charison ME. How do cancer patients who try to take control of their disease differ from those who do not? European Journal of Cancer Care 2004;13:219-226

5. Schmid-Büchi S, Dassen T, Halfens RJ. Experiencing the disease of breast cancer and getting life under control again. Pflege. 2005 Dec; 18: 345-352.

6. Kayser K, Sormanti M, Strainchamps E. Women coping with cancer. Psychology of Women Quarterly. 1999; 23: 725-39.

7. National Cancer Control Programme. Cancer incidence data: Sri Lanka Year 2000. Maharagama: National Cancer Control Programme, Government Cancer Institute; 2008.

8. Compus BE, Luecken L. Psychological adjustment to breast cancer. Current Directions in Psychological Science. 2002 June; 11: 111-114.

9. Hegel M.T, Moore CP, Collins ED, Kearing S, Gillock K.L, Riggs RL, Clay KF, Ahles TA. Distress, Psychiatric syndromes, and impairment of function in women with newly diagnosed breast cancer. Cancer 2006 Dec 15; 107: 2924-2931.

10. Burgess C, Cornelius V, Love S, Graham J, Richards M, Ramirez A. Depression and anxiety in women with early breast cancer: five year observational cohort study. British Medical Journal 2005 Mar; 330(7493): 702. Epub 2005 Feb 4.

11. Greer S, Morris T, Pettingale KW. Psychological response to breast cancer: effect on outcome. Lancet 1979, 2: 785-7.

12. Levy SM, Lee J, Bagley C, Lippman M. Survival hazards analysis in first recurrent breast cancer patients: seven year follow up. Psychosomatic Medicine 1988, 50: 520-8.

13. Cowan C. Hoskin R. Information preferences of women receiving chemotherapy for breast cancer. European Journal of Cancer Care 2007 Nov; 16: 543-50. 